IZA DP No. 7383

The Impact of Risk Perception and Risk Attitudes on Corrupt Behavior: Evidence from a Petty Corruption Experiment

Behnud M. Djawadi

René Fahr

May 2013 


\title{
The Impact of Risk Perception and Risk Attitudes on Corrupt Behavior: Evidence from a Petty Corruption Experiment
}

\author{
Behnud M. Djawadi \\ University of Paderborn \\ René Fahr \\ University of Paderborn \\ and IZA
}

Discussion Paper No. 7383
May 2013

IZA

P.O. Box 7240

53072 Bonn

Germany

Phone: +49-228-3894-0

Fax: +49-228-3894-180

E-mail: iza@iza.org

\begin{abstract}
Any opinions expressed here are those of the author(s) and not those of IZA. Research published in this series may include views on policy, but the institute itself takes no institutional policy positions. The IZA research network is committed to the IZA Guiding Principles of Research Integrity.

The Institute for the Study of Labor (IZA) in Bonn is a local and virtual international research center and a place of communication between science, politics and business. IZA is an independent nonprofit organization supported by Deutsche Post Foundation. The center is associated with the University of Bonn and offers a stimulating research environment through its international network, workshops and conferences, data service, project support, research visits and doctoral program. IZA engages in (i) original and internationally competitive research in all fields of labor economics, (ii) development of policy concepts, and (iii) dissemination of research results and concepts to the interested public.
\end{abstract}

IZA Discussion Papers often represent preliminary work and are circulated to encourage discussion. Citation of such a paper should account for its provisional character. A revised version may be available directly from the author. 


\section{ABSTRACT
The Impact of Risk Perception and Risk Attitudes on Corrupt Behavior: Evidence from a Petty Corruption Experiment ${ }^{*}$

We investigate one possible explanation for observed rates of corrupt behavior namely that individual decision makers who frequently engage in illegal actions may underestimate the overall probability of being caught. This might in particular be true for petty corruption where small amounts of bribes are involved and the detection rate is rather low. To abstract from confounding effects of reciprocal behavior, we design an experiment where a public official decides upon accepting a bribe that leads to a higher present period income while facing the risk of being audited and being left with a considerable lower income in all subsequent periods. Because risk attitudes might differ when putting earned versus endowed income at risk, we compare treatments where participants either receive an endowment beforehand, or earn their income by conducting a real effort task in every period. Independent of the treatments we already find high rates of corruption in very early periods. Risk attitudes measured with a subsequent lottery-choice experiment do not correlate with the behavior observed in the corruption experiment. We explain our findings by a systematic underestimation of the overall probability of being audited. Although detection probability is small in each period, the probability of being caught only once is substantially high when engaging in corrupt behavior on a regular basis. Our findings have important political implications because the underestimation of the total risk involved in engaging in corrupt behavior might nullify measures to fight petty corruption by increased governmental auditing.

JEL Classification: D73, C91, D81, K4

Keywords: petty corruption, risk, choice bracketing, experimental economics

Corresponding author:

René Fahr

Chair for Corporate Governance

Department of Management

University of Paderborn

Warburger Str. 100

D-33098 Paderborn

Germany

E-mail: rene.fahr@wiwi.uni-paderborn.de

\footnotetext{
* We are grateful for the University of Paderborn providing funds to finance the experiments. We thank participants at the Economics Science Association European Conference 2011 in Luxembourg, at the Vereinstagung 2012 in Göttingen, the TKI external seminar at the Utrecht School of Economics, the $7^{\text {th }}$ Alhambra Workshop in Granada, the $11^{\text {th }}$ Economics of Corruption Workshop in Passau and seminars at the University of Paderborn and the University of Cologne for helpful comments. In particular we are grateful for the comments by Klaus Abbink, Gary Charness, Clemens Kool, Johann Graf Lambsdorff, Katrin Muehlfeld, Johannes Münster and Ulrich W. Thonemann.
} 


\section{Introduction}

Putting moral considerations aside, the decision to engage in corrupt behavior is a gamble (Cadot 1987). In the case of petty corruption, where the bureaucrat accepts small amounts of bribes from the public, the bureaucrat takes his decision under partial equilibrium assumptions, i.e. he takes the detection probability as given. Thus, the public official's decision represents the decision when playing a compound lottery. To which extent does the misperception of risk on the side of the corrupt bureaucrat influence the decision to engage in corrupt behavior? Evaluating the detection probability in narrow brackets of only a few periods (Read/Loewenstein/Rabin 1999) might lead to an underestimation of the total risk involved in engaging in corrupt behavior, thus nullifying measures to fight petty corruption by increased auditing. To investigate this question, we run experiments where a public official decides upon accepting a bribe when being confronted with a government agency charged with uncovering corrupt public officials. Basically, we investigate the individual decision in a repeated lottery to learn how misperceptions of risk contribute to the observed level of corruption in our experiment. The only study we are aware of which investigates the role of risk perception and risk attitude on corrupt behavior is Berninghaus et al. (2010). In their experimental study, Berninghaus et al. (2010) investigate the decision to accept a bribe when the degree of uncertainty varies whereby corruption is modelled as a coordination game between six bureaucrats.

Corruption, defined as the misuse of public office for personal gain (Jain 2001), is a global problem with serious and crucial influence, not only on the affected country but also on other nations. It hampers the economic development of countries and thus the improvement of living standards (OECD report 2006). Further, the degree of corruption has a significant effect on the Gross National Product of some developing countries where bureaucracy is high and transparency in laws and regulations low (Shleifer/Vishny 1993). As corruption is widely recognized as a major economic problem around the world with an amount of about one trillion USD paid in bribes each year ${ }^{1}$, there is also a growing interest in the economic analysis of its causes and consequences starting with the pioneering work by Rose-Ackerman (1975). There are different classifications of corruption (Jain 2001, Serra 2010). In contrast to grand (political) corruption, petty corruption refers to the situation where typically lower

\footnotetext{
${ }^{1}$ http://go.worldbank.org/LJA29GHA80.
} 
level bureaucrats misuse their public office for private gain. The bribes which are involved in these illegal interactions are usually of small size and accepted on a frequent basis. Jain describes petty corruption as a circumstance where the public is required to bribe bureaucrats to make them do what they have to do anyway or to speed up the bureaucratic process (Jain 2001). Additionally, bribes that are offered by private citizens to lower level public officials for receiving special treatment, to which they are otherwise not legally entitled to, can be summarized as petty corruption. An illustrative example of petty corruption can be found in Bardhan (2006): "If you go to India, to any city, in many street corners, where there are traffic police officers, their one hand directing traffic and the other hand often stretched out, all the passing lorries contributing small amounts, piffling amounts; but you see that all the time and you gain a perception about how corrupt that country is.”2

Petty corruption is in particular a problem in developing and transition countries (Transparency International 2010). There are first attempts to analyze field data from developing countries with high levels of petty corruption (Fisman/Svensson 2007, Foltz/Bromley 2011). Moreover, there is a consensus in this literature as well as in studies analyzing data on the macro level (see Lambsdorff 2006 and the references therein) that petty corruption has an economically relevant negative impact on growth caused by foreign investors who are deterred by the level of petty corruption in a country (Fisman/Svensson 2007). Still, the literature investigating the microeconomic drivers of petty corruption is in its early stages. Information on the individual decision process would be helpful to assess the efficacy of measures to fight corruption. Building on the theoretical model of Becker and Stigler (1974), several empirical studies investigate monitoring and punishment as a means of reducing corruption. Di Tella and Schargrodsky (2003) find that higher wages combined with increased monitoring changed the behavior of formerly corrupt hospital employees. A field experiment by Olken (2007) revealed that increasing the level of monitoring by a government agency reduces corruption even in highly corrupt environments. In a similar spirit Fisman and Miguel (2007) analyze parking violations of diplomats in New York and find that the enforcement of unpaid parking violations reduced parking violations even by diplomats from high corruption countries. In a corruption experiment with participants from two different cultures, the USA and Pakistan, Banuri and

\footnotetext{
${ }^{2}$ Many more examples of petty corruption in India can be found at the website http://www.ipaidabribe.com/.
} 
Eckel (2012) investigate the effect of short term punishment. Banuri and Eckel conclude that corruption norms may not be intrinsic in a culture but rather incentive driven. Accordingly, punishment shifts incentives away from corrupt behavior, however somewhat varying between different cultures. A sustainable impact on the corruption level is only found when reasonable monitoring from government agencies is in place. When top-down monitoring is found to have such an important role in combating corruption, the question arises of how far these findings are relevant for the case of regular bribes as in the case of petty corruption. In particular, detailed knowledge of the individual risk perception in the case of compound lotteries is of high political relevance in order to assess the efficacy of governmental monitoring.

The present study contributes to the experimental literature on corruption (see for overviews Abbink 2006, Dusek/Ortmann/Lizal 2005, Serra 2010 and Serra/Wantchekon 2012). While several studies have identified the significant impact of risk and fear of punishment on corrupt behavior, little effort has been made to systematically tackle the specific features of risk in connection with petty corruption. A briber or official caught in the act faces severe punishment, not only in the form of fines or prison sentences, but also in the form of losing his job and/or pension. Being caught once is thus terminal, no matter when it happens. This potentially generates an anomaly: While the single probability of being caught in a particular act may be small, the probability of being caught at any time in the career is necessarily much higher and may be substantial. Previous research (Abbink/Irlenbusch/Renner 2002) suggests that the small single probabilities lead decision makers to underestimate the overall risk, though the overall risk is what really matters. We wish to systematically analyze risk-taking behavior under these circumstances, an effort that has not been made so far, neither in the literature on corruption nor in the more general research on decision-making under risk and uncertainty. By investigating a cognitive bias common across cultures the present paper complements the recent experimental studies on culture and corrupt behavior by Cameron et al. (2010), Barr and Serra (2010), and Banuri and Eckel (2012).

In the next section we discuss experimental literature related to risk perception and relate that to our experimental model of petty corruption. Section 3 derives the hypotheses. The experimental 
design and procedure is explained in section 4. The results are explained in section 5 and section 6 concludes.

\section{Petty corruption in the experimental lab and the role of risk perceptions}

As petty corruption is characterized by situations where bribes are frequently offered exposing the bribe taker to the same risk over and over again, the correct assessment of the overall risk of getting caught somewhere along the career is of major importance. The correct perception and evaluation of risk and uncertainty has been subject to many studies from cognitive psychology and behavioral economics (see for a short overview: Kahneman/ Tversky 1971, 1973, 1983, Charness/Levin 2005, Frederick 2005, Dohmen et al. 2010). However, these studies suggest that people lack the ability to form beliefs about the likelihood of events which are consistent with the basic rules of probability theory, especially with regards to joint and conditional probabilities.

Read, Loewenstein and Rabin (1999) argue with their concept of "choice bracketing” that these misperceptions occur because the choices available for the decision maker are mostly seen independently, thus being isolated from each other. Here, the authors speak of "narrow bracketing" since only few choices are taken into account, only leading to a locally optimal decision. If instead the choices are integrated within an amplified scope comparing the consequence of one choice with respect to any other in the choice set, a globally optimal decision will result. Bracketing the choices in this manner is called "broad bracketing". To the knowledge of the authors, there are only two studies in the experimental literature which notice this behavioral anomaly in connection with corruption.

Abbink, Irlenbusch and Renner (2002) state in their experimental bribery game that subjects significantly tend to "[...] underestimate the overall probability of disqualification". To be more specific, the subjects were asked to give an estimation of the overall probability of disqualification for three different detection probabilities and three different time horizons after the experiment was conducted. For almost every of these nine detection probability and time horizon combinations, the subjects underestimated the overall probability of disqualification, in some cases severely by more than 300\%. This is in line with a remark by Kirchgässner (1997) who pointed out that people - 
especially in the context of small briberies and corruptive actions - regularly tend to underestimate the detection rate and therefore take the risk of being punished when their corrupt behavior is revealed.

Regarding petty corruption, the question evolves whether the repeated act of taking bribes is separated into single independent decisions, or whether the consequences of current decisions to future outcomes are already included and integrated in the possible choice set. Let us illustrate the role of risk perception using our experimental petty corruption set-up. In fact, we analyze decisions in a repeated binary lottery. Assume that a low-level bureaucrat receives an income of 80 units which will increase by $25 \%$ if he accepts a bribe. However, this act is detected with a probability of $20 \%$ and in all remaining time periods his income, if detected, will be reduced to 20 units. ${ }^{3}$ Further, bribes can no longer be taken in future periods. According to standard economic theory, it is optimal to accept the bribe as a risk neutral decision maker, when evaluating only one time period. The expected value of 96 units (accepting the bribe) exceeds 80 units (rejecting the bribe). If we expand the time horizon to two time periods it still holds that taking the bribe once in the first time period gives a higher expected value than rejecting the bribe twice (164 units vs. 160 units). However, if the time horizon consists of three time periods, taking the bribe once in the first period gives a lower expected payoff than rejecting the bribe three times (232 units vs. 240 units). Hence, when considering three time periods, accepting the bribe once in the first period does not any longer constitute an optimal choice. Now, let us consider the case of accepting the bribe in two consecutive periods. If we consider a time horizon of two time periods, accepting the bribe twice is better than always rejecting it (176.8 units vs. 160 units). But, when considering a time horizon of three periods, accepting the bribe twice does not any longer constitute an optimal choice, since rejecting the bribe in each of the three periods yields a higher payoff (219.84 units vs. 240 units). From these considerations it follows that taking the bribe is the optimal choice for a risk neutral decision maker only with less than three remaining periods.

To avoid any confounding effects from social norms and differing ethical attitudes, we implement this corruption set-up in a neutrally framed economic experiment as in Abbink/ Henning-Schmidt (2006)

\footnotetext{
${ }^{3}$ Note, that our experimental model only allows catching the bureaucrats in the act of accepting the bribe. Typically, during audits, corruption which occurred many years before is detected and punished. If our model accounted for the possibility to detect and punish corrupt behavior in earlier periods, the risk associated with accepting a bribe would increase even further. Therefore, our experimental corruption model will allow assessing a lower bound of the impact of risk on corrupt behavior. We thank Clemens Kool for pointing that out.
} 
and in Berninghaus et al. (2010). By investigating this corruption set-up in the experimental laboratory along with measuring the individual risk attitudes using a multiple price list (Dohmen et al. 2010), we will be able to analyze whether corrupt behavior is the result of misperceptions of compound risk.

\section{Hypotheses}

There is clear evidence from the literature discussed above that people frequently violate the laws of probability and misjudge events under risk and uncertainty. As the sequence of possible decisions is characterized by compound risk we expect that the first bribe will be already accepted in those periods where rejecting bribes constitutes a dominant strategy. Our first hypothesis is therefore:

\section{H1: The first bribe is accepted in earlier periods than predicted by expected utility theory.}

When looking at decisions under risk and uncertainty, the attitude towards risk is a key aspect which must be addressed. This attitude - whether being risk-averse, risk-neutral or risk-seeking - is hereby strongly linked to the decision maker's personality and therefore plays an important role in the decision making process, especially if large losses in form of severe punishments are at stake. The psychological literature further suggests placing risk perception and risk attitudes into a broad psychological context. Accordingly, Frederick (2005) reports of a significant connection between a person's cognitive ability and the decision this person makes, especially if related to risk and uncertainty. Goeree, Holt and Palfrey (2003) provide evidence that risk attitudes and decisions in the main experiment are aligned with each other. Thus, to clearly disentangle the effect of erroneous risk perception on the decision of taking bribes we control for risk attitudes as measured with the binary lottery framework by Dohmen et al. (2010). According to the discussion above our second hypothesis is:

H2: A higher degree of risk aversion leads subjects to accept the first bribe in later periods.

There is literature providing evidence on the macro and micro level that women are less tolerant for corrupt transactions and less likely to be involved in corrupt behavior (with early works by Swamy et 
al. 2001 and Dollar/Fisman/Gatti 2001). ${ }^{4}$ Studies explain observed gender differences in behavior by the generally higher moral integrity of women, by different attitudes between men and women towards corrupt activities, by the women's exclusion from men dominated networks which foster corruption, by the individual's role in society and the degree of participation in the public domain (see for overviews about gender and corruption Chaudhuri 2012 and Frank/Lambsdorff/Boehm 2011). Experimental evidence suggests that women behave more opportunistically in corrupt relationships and reciprocate less, once they receive a bribe compared to their male counterparts (Lambsdorff/Frank 2010, 2011). This hampers corruption in the long run as the briber will possibly not interact with the same bribee again who pockets the bribe but does not deliver the service. As our experiment is framed in a neutral setting, any differences in the behavior of women compared to men cannot be explained by higher moral awareness. Further, our design rules out any form of reciprocity and thus opportunistic behavior cannot serve as a potential candidate for possible gender differences either. However, divergent levels of corruption might be partially due to different risk attitudes of men and women. In particular, there is evidence that the average female avoids risky behavior (see Eckel/Grossman 2008 and Croson/Gneezy 2009 for excellent overviews and ample evidence along these lines). ${ }^{5}$ Frank und Schulze (2003) support this finding. In their experimental investigation they entirely focus on the behavior of the public officials and show that once a detection probability is established women in the role of the bribee are significantly less willing to accept the bribe compared to men (Schulze/Frank 2003). The authors explain these findings by women’s higher risk aversion as in their first experimental set-up, with no detection probability at all, women did not show any difference in behavior compared to men (Frank/Schulze 2000).

Hence, we have reasons to expect that systematic gender differences can occur as women who are more risk averse than men will be less willing to incline in risky situations and accept bribes less frequently than men. We therefore state the following additional hypothesis:

\footnotetext{
${ }^{4}$ This finding has been challenged by recent experimental evidence, according to which more ethical behavior shown by women can only be supported for western cultures like Australia but not for India, Indonesia and Singapore (Alatas et al. 2009). Waithima (2010) who replicates the study by Alatas et al. (2009) uses a sample of 1,012 students in Kenya and also finds no gender differences in behavior.

${ }^{5}$ There are notable exceptions however. Booth and Nolen (2010) find evidence that the risk taking gap vanishes when women went to single sex schools. Gneezy et al. (2010) find women more risk taking than men in a maternalinear society.
} 


\section{H2': Female participants accept the first bribe in later periods than male participants.}

Another important issue concerns the nature of income that subjects receive in the lab. Experimental studies show that if subjects have to work for their money by solving a real effort task, their decisions in the experiment are likely to be different than in situations where they are endowed with money from the experimenter. Boylan and Sprinkle (2001) examine whether it makes a difference in tax payers' decisions on reporting taxable income if this income is either earned or endowed. They find that subjects who earned their income are less willing to take the risk of evading taxes and therefore report their taxable income more truthfully. Further, Cherry, Frykblom and Shogren (2002) point out the importance of earned income and state with respect to bargaining experiments that "only legitimate assets produce rational behavior”. Arkes et al. (1994) and Thaler and Johnson (1990) provide further evidence that unearned income leads to more risky behavior. Again, to clearly identify the effect of risk misperception on corrupt behavior we control for the source of income and come up with two different treatments. In one treatment (earned income) subjects earn their income by solving a real effort task consisting of positioning sliders (Gill/Prowse 2012). In the second treatment (endowed income) subjects are endowed by the experimenter. Following the observation in pre-tests, the real effort task is chosen in a way that the average income in the real effort treatment is about the amount of the endowed income treatment. Moreover, the real effort task is chosen in a way that the exerted effort of the participants directly generates income, excluding the influence of luck or (changing) external conditions. By giving the participants an insight into their performance in a trial round, they should be able to form clear expectations from round to round about the income they are able to generate in the next round. The effect of earned income on corrupt behavior has not been investigated yet. Thus, the present paper makes a methodological contribution to the experimental literature on corruption.

In line with the existing literature we expect subjects with an earned income to take fewer risks than subjects with an endowed income. Thus our corresponding hypothesis is:

H3: The first bribe in the earned income treatment is accepted in later periods than in the endowed income treatment. 


\section{Experimental design and procedure}

\section{Experimental Design}

We design our experiment as an individual decision-making process under risk and uncertainty. Since only the behavior of the bribee in this anonymous petty corruption setting is of importance, we exclude any reciprocity issues by modeling the briber as being exogenous and the bribes being offered to the bribee at a constant rate. Thus, it is assumed that the briber always has an advantage of paying the bribe. The bribee frequently faces the risk of getting caught if the bribe being offered is accepted, and once detected somewhere along the time horizon, his career will be over. This entails that although the single probability of getting caught when the bribe is accepted once might be sufficiently small, by accepting the bribes on a frequent basis the overall probability of not getting caught somewhere in the career diminishes sharply. In our design with a time horizon of ten periods, subjects receive an income in every period first and afterwards have the option to take or refuse an additional payment representing the bribe that comes at a risk. The sequence of events is shown in Figure 1. In the main treatment (earned income treatment: EARNED) subjects have to earn their income by performing a real effort task; in the control treatment (endowed income treatment: ENDOWED) subjects are endowed with their income. The real effort task is to position a set of sliders correctly in the middle of the slider bar in a specific amount of time (Gill and Prowse 2012). For each correctly positioned slider a constant amount of the experimental currency "Taler" is added to the subject's current income. Having received their income by real effort or by endowment, subjects are then given the option to accept a risky additional payment or to refrain from it. In the case of abstaining from accepting the additional payment, the current income remains unchanged and the next period starts as before. However, if one subject opts for the additional payment, the following implications result: with a probability of $80 \%$ the current income is increased by one fourth and the next period starts as before, corresponding to a situation where a bribe is accepted without getting caught by the authorities. With the counter probability of $20 \%$ though, the subject will not get the additional payment. In addition to that, only a small fraction of the previous income is received in all subsequent periods, and opting for the additional payment is not possible anymore. This represents the situation where a bribe payment is detected by the authorities. The severe consequences are in line with the existing literature, assuming 
that a corrupt public official once caught will be fired immediately and gets a job which is paid lower somewhere in the private sector for the rest of his working life (van Rijckeghem/Weder 2001). It is additionally assumed that these former public officials are stigmatized and severely monitored in their subsequent career so that engaging in illegal activities again is not possible anymore.

Figure 1: Experimental design

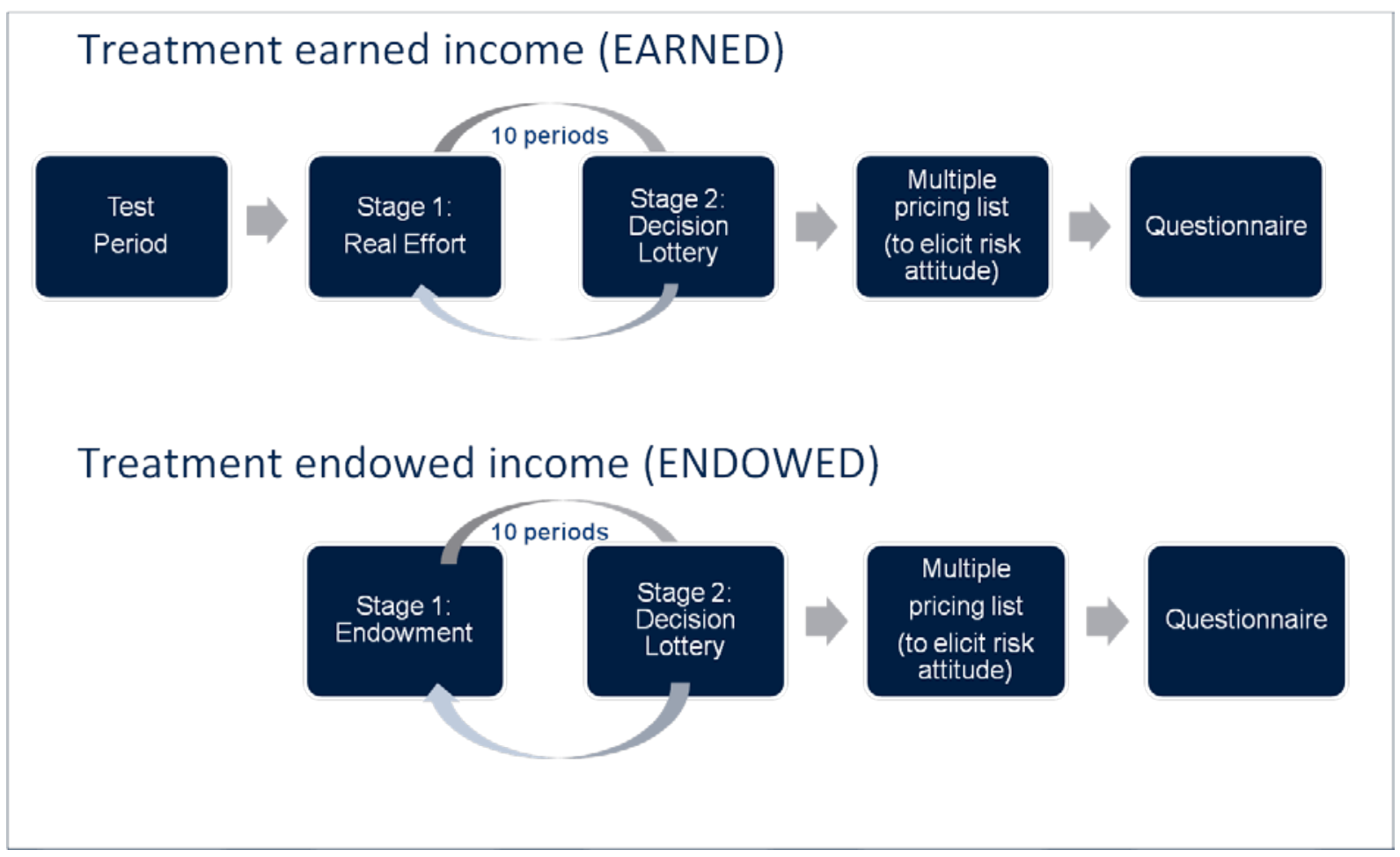

\section{Procedure}

The experiment was conducted in July 2010 and August 2011 at the Business and Economic Research Laboratory (BaER-Lab) at the University of Paderborn and computerized using the software z-Tree (Fischbacher 2007). Overall 109 subjects, mainly studying economics and business administration, participated in four sessions, two sessions for each of the two treatments. Subjects were recruited by the online recruiting system ORSEE (Greiner 2004) and were only allowed to participate in one session. 55 subjects participated in the earned income treatment, whereas 54 subjects participated in the endowed income treatment. After each subject was seated randomly to a computer workplace in a cubicle detached from each other, all subjects received the same introductory talk and were told not to communicate during the session. Instructions were then distributed and time for a careful reading was granted. We decided to use neutral instructions to avoid any connotations that might be associated 
with corrupt actions and as a consequence might affect subjects' behavior and decisions in an uncontrolled way. ${ }^{6}$ In EARNED, subjects had two minutes to position as many of the 48 sliders as possible shown to them on the computer screen. For each correctly positioned slider a constant amount of 4 Talers was added to their current income. To get familiar with the task, prior to the first period the subjects were given the opportunity to practice with the sliders for the duration of two minutes. ${ }^{7}$ This practice round was unpaid. Subjects in ENDOWED were straightaway endowed with 80 Talers in each period. If a subject accepted the additional payment in one period, however was detected, the potentially earned income in each subsequent period respectively was lowered in the following way: In EARNED the number of sliders was decreased from 48 sliders to only 10 sliders where for each correctly slider an amount of 2 Talers was paid. Equivalently, in ENDOWED the endowed income was lowered from previously 80 Talers to only 20 Talers. Further the option whether to accept the additional payment or not was excluded for all remaining periods. The payoffs in each period were summed up and exchanged to Euro with a rate of 100 Talers per Euro along with an additional showup fee of $2.50 €$. After the main experiment, subjects were asked to answer a questionnaire which was divided into two parts. In the first part risk preferences were elicited by using the incentivized lottery choice framework by Dohmen et al. (2010), followed by an unpaid second part with questions on the socio-economic background of the participants, e.g. age, gender, field of study etc. Each session lasted for about 1 hour and subjects earned on average $13 €$.

\section{Results}

A key indicator of any misperception of compound risk in our experimental set-up is the timing of accepting the first and second bribe in the experiment. Further, to learn about the appropriate method to test our hypotheses we need to investigate whether the decision of the subjects in the experiment represent a clear pattern, i.e. do the individuals who accept a bribe for the first time continue to do so in the remaining periods.

\footnotetext{
${ }^{6}$ However, Abbink and Henning-Schmidt (2006) do not find differences in corruption experiments with loaded framing compared to neutral framing.

${ }^{7}$ A couple of weeks before the first experiments we conducted a pilot test with 20 participants to find out how many sliders can be positioned correctly within two minutes on average. The average amount of sliders was 20 , so we used this number to calculate a comparable, average income in the endowed income treatment.
} 


\section{Descriptive Statistics}

Table 1 lists the numbers separated by those who did not accept the bribe in the first period and those who did. 16 subjects already accept the bribe in the first period. In total, 85 subjects who represent $78 \%$ of the complete sample show a stable pattern. They either stick to their decision over all periods by accepting the bribe in every period or in no round at all, or change their behavior only once by accepting the bribe in every subsequent period after one specific round. Only 6 subjects show a very unstable pattern of 4 or more switches between accepting and not accepting the bribe. Those who already accept the bribe in the first period only show an even number of switches, i.e. they eventually accept the bribe after having refrained from it in earlier periods. Besides a few exceptions (3 subjects switching never and 1 subject switching four times) the uneven number of switches reveals that the majority of subjects, who accept the bribe later than in the first period, end up accepting the bribe frequently towards the end.

Table 1: Patterns of accepting the bribe

\begin{tabular}{|c|c|c|c|c|}
\hline & \multicolumn{2}{|c|}{ Did NOT accept bribe in the first period } & \multicolumn{2}{c|}{ Already accepted bribe in the first period } \\
\hline number of switches & frequency (\%) & $\sum$ in \% & frequency (\%) & $\sum$ in \% \\
\hline 0 & $3(3.23)$ & 3.23 & $12(75)$ & 75 \\
\hline 1 & $70(75.27)$ & 78.49 & $3(18.75)$ & 93.75 \\
\hline 2 & $15(16.13)$ & & & \\
\hline 3 & $1(1.08)$ & 94.62 & & \\
\hline 4 & $4(4.30)$ & 95.7 & & 100 \\
\hline 5 & & 100 & & \\
\hline
\end{tabular}

Note: Switching means changing behavior either from not accepting the bribe to accepting the bribe when comparing the actual period to the preceding period or the other way around. $15(12+3)$ participants take the bribe in every period or no period, 70 participants who do not accept the payment in the first period, have only one switching point, implying that they continue to accept the bribe after having accepted it once.

Table 2 provides an overview on the period in which subjects accept the bribe for the first time and the period for the second time. As we can see, only 10 subjects follow the rational behavior of a risk neutral expected utility maximizer and accept the bribe for the first time in period 9 and continue to do so in period $10 .{ }^{8}$ Anticipating our remaining analysis, this unusual high number of first acceptances is

\footnotetext{
${ }^{8}$ See Appendix B for detailed calculus why risk neutral expected utility maximizers accept the first (second) bribe in period 9 (period 10).
} 
not due to risk preferences, because only 7 out of 107 subjects exhibit a risk seeking profile. Table 2 already indicates evidence in favor of hypothesis H1.

Table 2: In which period do subjects accept the bribe for the first time and in which period for the second time?

\begin{tabular}{|c|c|c|c|c|c|c|c|c|c|c|}
\hline first time & & & & & & time & & & & \\
\hline & 2 & 3 & 4 & 5 & 6 & 7 & 8 & 9 & 10 & total $(\%)$ \\
\hline 1 & 9 & 1 & & & & & 1 & 1 & & $\begin{array}{c}12 \\
(16.44) \\
\end{array}$ \\
\hline 2 & & 2 & & 1 & & & & & & $\begin{array}{c}3 \\
(4.11) \\
\end{array}$ \\
\hline 3 & & & 2 & 1 & 1 & & & & 1 & $\begin{array}{c}5 \\
(6.85) \\
\end{array}$ \\
\hline 4 & & & & 1 & & & 1 & 1 & & $\begin{array}{c}3 \\
(4.11)\end{array}$ \\
\hline 5 & & & & & 4 & & 1 & & & $\begin{array}{c}5 \\
(6.85)\end{array}$ \\
\hline 6 & & & & & & 9 & 3 & & & $\begin{array}{c}12 \\
(16.44)\end{array}$ \\
\hline 7 & & & & & & & 8 & 3 & & $\begin{array}{c}11 \\
(15.06) \\
\end{array}$ \\
\hline 8 & & & & & & & & 10 & 2 & $\begin{array}{c}12 \\
(16.44) \\
\end{array}$ \\
\hline 9 & & & & & & & & & 10 & $\begin{array}{c}10 \\
(13.7) \\
\end{array}$ \\
\hline total (\%) & $\begin{array}{c}9 \\
(12.33) \\
\end{array}$ & $\begin{array}{c}3 \\
(4.11) \\
\end{array}$ & $\begin{array}{c}2 \\
(2.74) \\
\end{array}$ & $\begin{array}{c}3 \\
(4.11) \\
\end{array}$ & $\begin{array}{c}5 \\
(6.85) \\
\end{array}$ & $\begin{array}{c}9 \\
(12.33) \\
\end{array}$ & $\begin{array}{c}14 \\
(19.18)\end{array}$ & $\begin{array}{c}15 \\
(20.55) \\
\end{array}$ & $\begin{array}{c}13 \\
(17.8)\end{array}$ & $\begin{array}{c}73 \\
(100) \\
\end{array}$ \\
\hline
\end{tabular}

Note: Three subjects did not take the bribe at all. 21 subjects were detected after taking the bribe for the first time and did not have the chance to accept it a second time. 12 subjects finished the experiment but accepted the bribe only once (although they had the chance to accept it a second time).

We test our hypotheses by evaluating the time periods in which bribes are taken the first and the second time respectively. Starting at period one, we determine for each period the proportion of subjects who have not accepted the first (second) bribe yet and compare the resulting curves or cumulative choice distributions with each other. ${ }^{9}$ The non-parametric Kolmogorov-Smirnov statistics (Lilliefors 1967) enables us to examine whether two cumulative distribution functions coming from two subsamples are different from each other with respect to the timing of accepting the first and second bribe. Accordingly, the one-sided test examines whether the cumulative distribution of one subsample is greater than the other which, in our case, then speaks on average for a later timing in accepting the bribe. We measure the D-value of the Kolomogorov-Smirnov test by calculating the

\footnotetext{
${ }^{9}$ Equivalently, we regard the time span between period 1 and the period of the first (second) accepted bribe as "survival time" which specifies the number of consecutive periods in which subjects refrain from taking the bribe. The period in which the bribe is taken is marked as "death" so that the underlying curves are nothing less than "survival functions" which can be compared with each other by using non-parametric methods like the Kolmogorov Smirnov Test (Lee 1992, DeGroot/Schervish 2012).
} 
difference between the proportions of any two curves in exactly that time period in which this difference is the largest (Siegel/Castellan Jr. 1988, DeGroot/Schervish 2012).

\section{Risk Perception and Corruption (H1)}

We perform a Binomial test to determine whether bribes are taken significantly earlier than expected utility theory would predict. Referring first to subjects who show a stable decision pattern in taking the bribe constantly from a particular period onwards, we see in Table 2 that only 10 out of 73 subjects accept the bribe in period 9 and the majority of 63 take the first bribe in earlier periods. Even if we take a conservative view and treat period 9 as one group and all the other previous periods together as a second group, assuming in both groups an equal distribution in the total numbers of accepted first bribes, this null hypothesis is clearly rejected (Binomial test with an event probability of 0.5 , $\mathrm{p}<0.0001$, two-sided). If we now account for the total sample excluding those who never accept a bribe or accept the bribe after period 9 we see that out of the remaining 94 subjects 80 already accept the bribe the first time before period 9. Thus, we reject the null hypothesis that the total number of accepted first bribes is equally distributed in period 9 and in the periods before (Binomial test with an event probability of $0.5, \mathrm{p}<0.0001$, two-sided).

Hence, our first hypothesis that first bribes are accepted earlier than predicted by expected utility theory is corroborated.

\section{Risk Attitudes and Corruption (H2)}

As indicated in the description of the experimental procedure, we elicit subjects' risk attitudes by using the binary lottery framework of Dohmen et al. (2010). Subjects are asked to fill out Table 3 deciding in each row whether they prefer a safe option (Option A) or an all-or-nothing lottery (Option B). In this table the payment that Option A yields increases from line to line by 1 Euro. To provide incentives, 2 subjects in each session were chosen by chance and were then paid for one random decision row of their table. 
We define 4 risk categories ranging from risk-averse (category 1) to risk seeking (category 4) and use the row where subjects switch once from the lottery (Option B) to the safe choice (Option A) as a sorting key to assign subjects to the risk categories. Specifically, if subjects switch before row 10 they are classified as being risk averse. If the switching row is between 11 and 13 (14 and 16) subjects are categorized as slightly risk averse (risk neutral). Finally, subjects switching after row 16 or never are characterized as being risk seeking. Table 4 shows the corresponding distribution of our sorting procedure.

Table 3: Lottery framework to measure risk attitude

\begin{tabular}{|l|ll|}
\hline & Option A & Option B \\
\hline 1$)$ & $0 €$ safe & $50 \%$ of winning $30 €, 50 \%$ of winning $0 €$ \\
\hline 2$)$ & $1 €$ safe & $50 \%$ of winning $30 €, 50 \%$ of winning $0 €$ \\
\hline 3$)$ & $2 €$ safe & $50 \%$ of winning $30 €, 50 \%$ of winning $0 €$ \\
\hline 4$)$ & $3 €$ safe & $50 \%$ of winning $30 €, 50 \%$ of winning $0 €$ \\
\hline 5$)$ & $4 €$ safe & $50 \%$ of winning $30 €, 50 \%$ of winning $0 €$ \\
\hline 6$)$ & $5 €$ safe & $50 \%$ of winning $30 €, 50 \%$ of winning $0 €$ \\
\hline$\ldots$ & & \\
\hline$\ldots$ & & $50 \%$ of winning $30 €, 50 \%$ of winning $0 €$ \\
\hline 19$)$ & $18 €$ safe & $50 \%$ of winning $30 €, 50 \%$ of winning $0 €$ \\
\hline 20$)$ & $19 €$ safe \\
\hline
\end{tabular}

Table 4: Distribution of risk categories

\begin{tabular}{|l|l|l|l|c|}
\hline risk category & $\begin{array}{l}\text { earned income } \\
\text { (EARNED): } \\
\text { \# of subjects (\%) }\end{array}$ & $\begin{array}{l}\text { endowed income } \\
\text { (ENDOWED): } \\
\text { \# of subjects (\%) }\end{array}$ & total (\%) & r-value \\
\hline risk averse & $15(27.27)$ & $16(30.77)$ & $31(28.97)$ & 0.554 \\
\hline slightly risk averse & $27(49.09)$ & $13(25)$ & $40(37.38)$ & 0.379 \\
\hline risk neutral & $11(20)$ & $18(34.62)$ & $29(27.1)$ & 0.082 \\
\hline risk seeking & $2(3.64)$ & $5(9.62)$ & $7(6.54)$ & -0.262 \\
\hline total (\%) & $55(51.4)$ & $52(48.6)$ & $107(100)$ & \\
\hline
\end{tabular}

Note: Two subjects were excluded from the analysis since their choices seem random.

To make sure that our sorting procedure is correct, we follow Holt/Laury (2002) and Goeree/Holt/Palfrey (2003) and apply maximum likelihood analysis to the binary lottery choices to 
infer the parameter of relative risk aversion. As shown in Goeree/Holt/Palfrey (2003) we use a utility function with constant relative risk aversion (CRRA) and capture the degree of risk aversion by evaluating the row where subjects switch from the lottery to the safe option. We also allow for noise as subjects may make errors in filling out the table and introduce a probabilistic choice function developed by Luce (1959) which has shown to approximate choice behavior in binary lottery frameworks quite well (Holt/Laury 2002, Goeree/Holt/Palfrey 2003) ${ }^{10}$. Table 4 reports the r-value for each risk category. Consistent with the literature, this coefficient takes a value below zero for the riskseeking type and is highest for the risk-averse type. Notice that each r-value falls almost exactly in intervals that were determined in the literature for assigning subjects to these risk groups defined above. ${ }^{11}$ Thus, we have strong support for our sorting procedure being correctly done. While the multiple price list at the end of the experiment is supposed to measure the risk attitudes independent from the experiences in the preceding experiment we check for any differences in Figure 2. This graph shows the proportion of Option B for each decision row in the two treatments.

Figure 2: Proportion of subjects playing the lottery across treatments (EARNED=treatment with earned income, ENDOWED=treatment with endowed income)

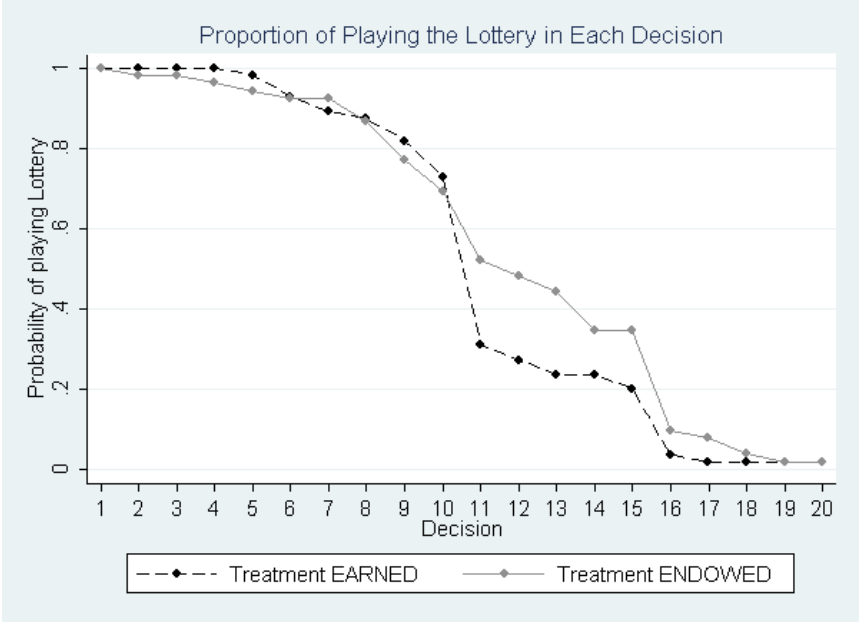

The Kolmogorov-Smirnov Test does not reject the null hypothesis that the lottery choice behavior in the treatments is not statistically different from each other $(\mathrm{D}=0.21, \mathrm{p}>0.1$ two-sided). Thus, in the

\footnotetext{
${ }^{10}$ Details on the derivation of the individual risk preferences can be found in Appendix C.

11 In fact our classification is consistent with the ranges provided in Holt/Laury (2002, Table 3) and Goree/Holt/Palfrey (2003, Table 5) with the exception of those classified as slightly risk averse. Our estimation of $\mathrm{r}$ : 0.379 for slightly risk averse subjects according to their lottery choices is somewhat above the range $0.09<\mathrm{r}<0.36$ defined in Goree/Holt/Palfrey (2003) but within the range defined in Holt/Laury (2002): $0.15<\mathrm{r}<0.41$.
} 
following, we pool our data across treatments with respect to risk attitude. To test $\mathrm{H} 2$ we determine the combined choice distributions of the risk-averse/slightly risk-averse type and compare it with the combined equivalent of the risk-neutral/risk-seeking type (see Figure 3).

Figure 3: Proportion of subjects which has not accepted the bribe yet for the first time across risk groups

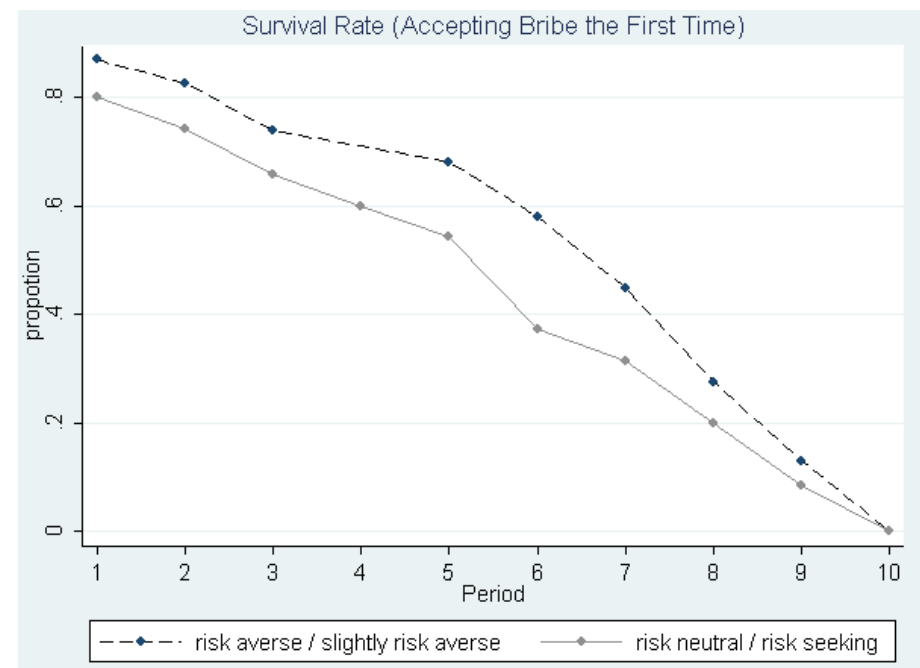

Note: The survival rate is defined as the proportion of subjects which has not accepted the first bribe yet.

Applying an additional Kolmogorov-Smirnov Test, the null hypothesis which states that these curves arose from the same distribution cannot be rejected either $(\mathrm{D}=0.208, \mathrm{p}>0.1$, one-sided). Thus, we cannot support the hypothesis stating that a higher degree of risk aversion leads subjects to accept the first bribe in later periods.

To clearly interpret these obtained results we investigate in the following whether risk preferences account for possible gender differences in our experiment. Figure 4 shows the proportion of lottery decisions in the framework divided by gender. Eye-ball inspection already provides some hints that women tend to switch earlier from the lottery to the safe option, compared to their male counterpart. The Kolmogorov-Smirnov Test indeed rejects the null hypothesis that the risk profiles are statistically the same ( $\mathrm{D}=0.3061, \mathrm{p}<0.05$, one-sided). Hence, we find compelling clues that women are more riskaverse than men. 
Figure 4: Proportion of subjects playing the lottery by gender

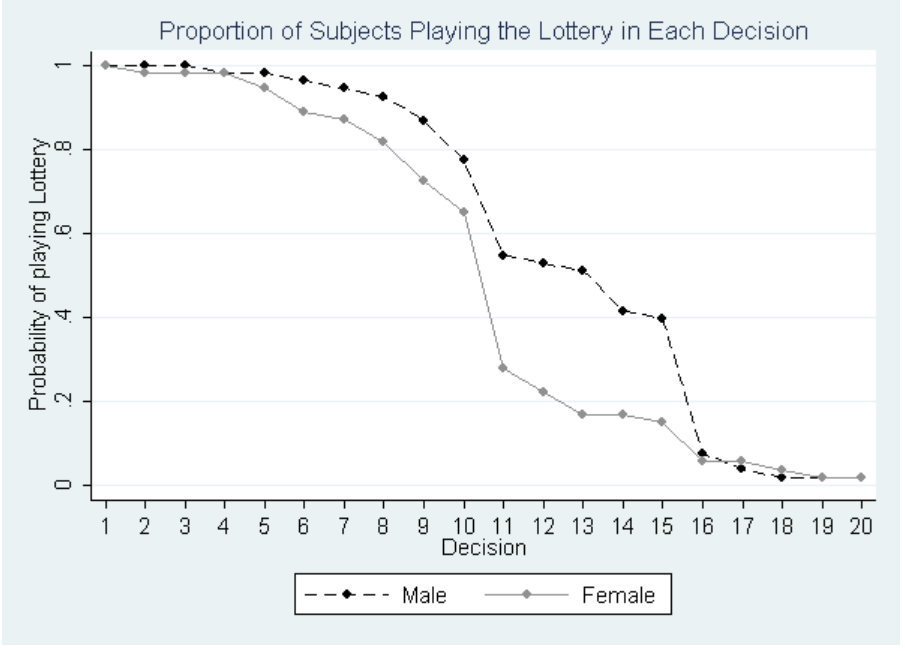

However, as figure 5 shows, the survival rates of the male and female subsample are virtually the same in the first four periods. Although a higher proportion of women rejects the bribe compared to men in periods 5 and 6, this behavioral pattern switches in the opposite direction from period 7 on, as men now tend to accept bribes later than women. Hence, we overall do not find any gender differences in the timing of when the bribe is accepted for the first time. Thus, we cannot support our hypothesis H2' stating that women who are in general more risk-averse than men are less willing to accept bribes. This finding challenges the results reported in Schulze and Frank (2003) but is consistent with the experimental studies of Lambsdorff and Frank (2010, 2011), Rivas (2013), Waithima (2010) and, to a large extent, of Alatas et al. (2009) who all find no gender differences in accepting bribes.

Figure 5: Proportion of subjects which has not accepted the bribe yet for the first time by gender

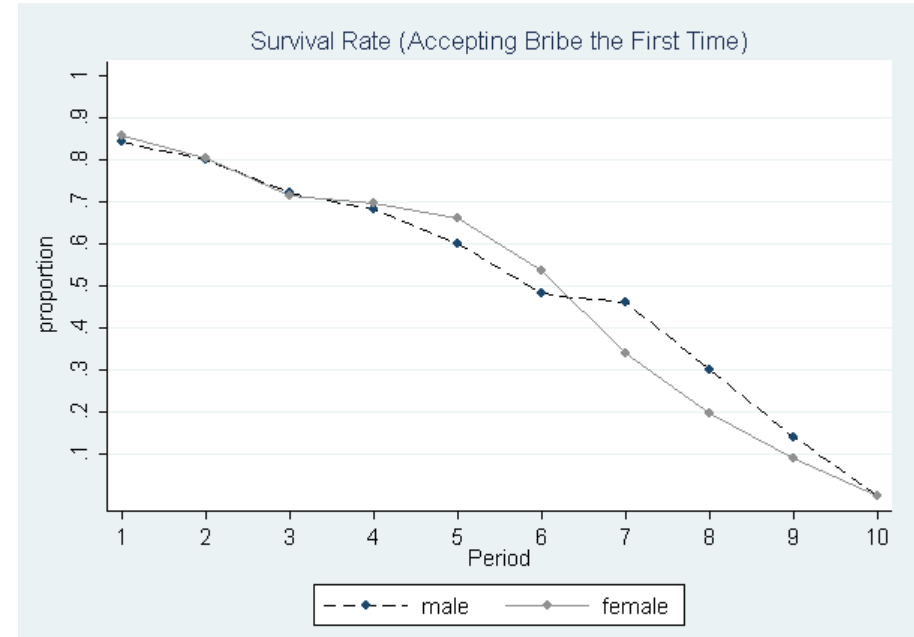

Note: The survival rate is defined as the proportion of subjects which has not accepted the first bribe yet. 
Source of Income and Corruption (H3)

Before we turn to our last hypothesis and compare the cumulative choice distributions between the EARNED and ENDOWED treatment, we check whether the underlying data are not biased by simple income effects or by any risk considerations implied by the variance of income in the EARNED treatment. For this, we first inspect some descriptive statistics. Table 5 shows that the median income is with about 100 Taler (4 Taler times 24.8) slightly higher than in the ENDOWED treatment. The standard deviation over the treatments is moderate with a median of about 3 . We therefore consider our design appropriate to test H3.

Table 5: Descriptive statistic over the performance in the slider task over all 10 periods (reported are number of sliders).

\begin{tabular}{|l|l|l|l|}
\hline & Mean & Sd & Median \\
\hline Men & 26.45 & 2.56 & 26.7 \\
\hline Women & 23.27 & 3.17 & 22.71 \\
\hline Total & 24.86 & 3.01 & 24.8 \\
\hline
\end{tabular}

To that end, we determine the choice distributions of our treatments separately and ascertain whether earned income leads subjects to take the first bribe in later periods than in the endowed counterpart. Figure 6 shows the two curves. In the first four periods the survival rates in the treatments EARNED and ENDOWED are very close to each other with minor differences in accepting the bribe for the first time. However, from period 5 onwards the survival rates in ENDOWED decrease much steeper indicating that a higher proportion of subjects accept the first bribe compared to those subjects in the EARNED treatment. In fact, the Kolmogorov-Smirnov Test rejects the null hypothesis stating that the two distribution functions do not differ statistically ( $\mathrm{D}=0.249, \mathrm{p}<0.05$, one-sided). Thus, overall, a significantly higher proportion of subjects in EARNED accept the first bribe in later periods compared to their counterparts in the ENDOWED treatment, supporting H3. If we now examine the choice distributions with respect to the timing of accepting the second bribe, we again observe that on average a higher proportion of subjects in EARNED accept the second bribe in later periods than in the ENDOWED treatment ( $\mathrm{D}=0.273, \mathrm{p}<0.1$, one-sided,). As can be seen from figure 7 this effect is not as large as for the timing of accepting the first bribe. 
Figure 6: Proportion of subjects which has not accepted the bribe yet for the first time across treatments

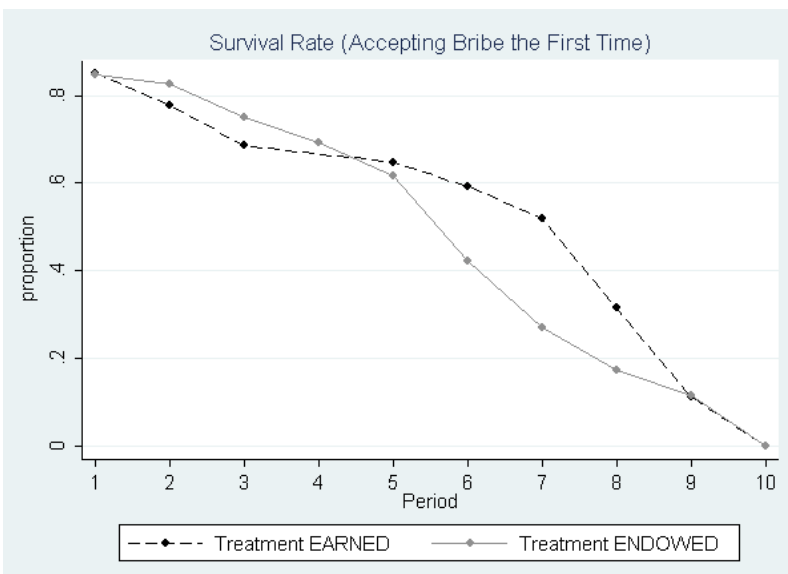

Figure 7: Proportion of subjects which has not accepted the bribe yet for the second time across treatments

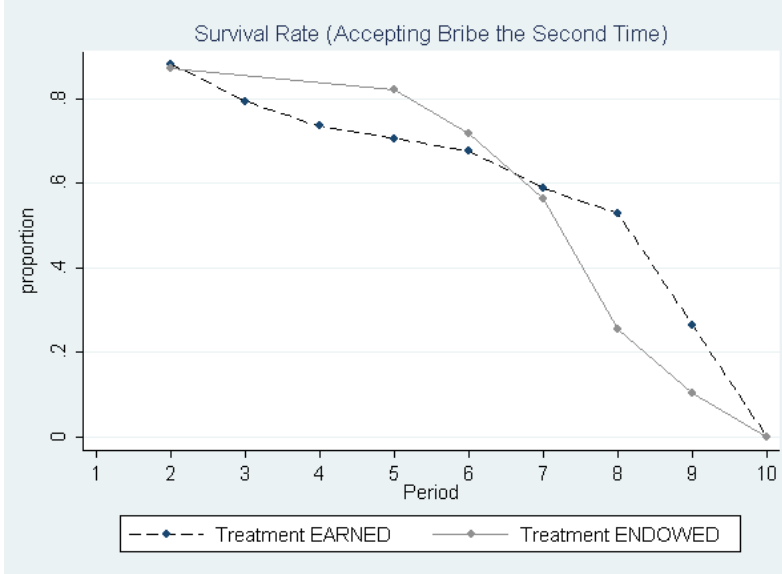

Note: In Figure 6 (Figure 7) the survival rate is defined as the proportion of subjects which has not accepted the first (second) bribe yet.

Overall, we regard hypothesis $\mathrm{H} 3$ as supported. In the experiment, earned income influences the decision and shifts the inclination to accept the first and the second bribe to later periods compared to the endowed income treatment.

\section{Discussion and conclusion}

Our experimental set-up allowed precisely identifying the role of risk perception on the decision to be involved in petty corruption. Given the high detection rate in our experimental set-up and the disastrous consequences for the bribee once detected, we find surprisingly high corruption rates at very early periods of the experiment. This behavior cannot be explained by the risk attitudes of the subjects. We determined these risk preferences by using an incentive-compatible lottery framework which is well established in the literature and found to explain certain behavior patterns in risky situations quite well. However, our results cannot support the hypothesis that risk attitudes influence the decision in the corruption game. This is in line with recent evidence reported in Berninghaus et al. (2010). Our study also contributes to the small literature on the relation between gender and corruption. Consistent with the literature, we do find that women are more risk-averse than men. However, with our design which abstracts corruption from any moral considerations and reduces the decision to accept a bribe to a mere risky decision our data do not reveal statistically significant 
evidence that women are in fact less corrupt by accepting the bribe in later periods than men. These results suggest that the overall risk involved in decisions resembling compound lotteries lead subjects to behave non-conformingly to their own risk profile. As our experimental design simulates a petty corruption situation these findings may imply that women in this context are as much prone to engage in illegal activities as men, despite exhibiting more risk aversion.

Lastly, we provide a methodological contribution to the experimental corruption literature by comparing an earned income with an endowed income treatment in our experiment. Similar to a related approach in the tax compliance literature (Boylan/Sprinkle 2001) we argue that this might lead to less corrupt behavior. We can in fact support the hypothesis that the bribe is accepted in later periods for the first and for the second time when subjects have to earn their income in the experiment compared to a condition where subjects are endowed with money from the experimenter. This would imply that future experimental studies on corruption should try to implement earned income conditions.

Previous research has shown that an increase in the audit rate and/or resolute penalties by governmental agencies is a highly recommended path to reduce corruption independent of the existing culture in the country (e.g. Olken 2007). Our findings indicate that the strong influence of misperceiving the involved risk needs to be taken into account when assessing the efficacy of increasing the monitoring by government agencies. Future experimental research might find out ways to allow individuals a better evaluation of the risk involved in illegal behavior. 


\section{References}

Abbink, K. (2006): Laboratory experiments on corruption. In: Rose-Ackerman, S. (ed.): The Handbook of Corruption. Edward Elgar Publishers, Cheltenham, UK and Northampton, US.

Abbink, K. and Henning-Schmidt, H. (2006): Neutral versus loaded instructions in a bribery experiment. Experimental Economics, 9, 103-121.

Abbink, K. Irlenbusch, B. and Renner, E. (2002): An Experimental Bribery Game. Journal of Law, Economics and Organization, 18, 428-454.

Alatas, V., Cameron, L., Chaudhuri, A., Erkal, N., and Gangadharan, L. (2009): Gender, Culture, and Corruption: Insights from an Experimental Analysis. Southern Economic Journal, 75, 663-680.

Arkes, H. R., Joyner, C. A., Pezzo, M.V., Nash, J. G., Siegel-Jacobs, K., and Stone, E. (1994). The psychology of windfall gains. Organizational Behavior and Human Decision Processes, 59, 331-347

Banuri, S. and Eckel, C. (2012): The Effects of Short-Term Punishment Institutions on Bribery: US versus Pakistan. CBEES Working Paper Series 11-05.

Bardhan, P. (2006): The Economist's Approach to the Problem of Corruption. World Development, 34, 341-348.

Barr, A. and Serra, D. (2009): The Effects of Externalities and Framing on a Petty Corruption Experiment. Experimental Economcis, 12, 488-503.

Barr, A. and Serra, D. (2010): Corruption and Culture: An Experimental Analysis. Journal of Public Economics, 94, 862-869.

Becker, G. and Stigler, G. (1974): Law Enforcement, Malfeasance, and the Compensation of Enforcers. Journal of Legal Studies, 3, 1-19.

Berninghaus, S., Haller, S., Krüger, T., Neumann, T., Schosser, S. and Vogt, B. (2010): Risk attitude, beliefs, and information in a corruption game - An experimental analysis. KIT Working Paper Series in Economics No. 6.

Booth, A.L., and Nolen, P.J. (2010): Gender Differences in Risk Behaviour: Does Nurture Matter? Economic Journal, 122 (558), F56-F78.

Boylan, S. J. and Sprinkle, G. B. (2001): Experimental evidence on the relation between tax rates and compliance: The effect of earned vs. endowed income. Journal of the American Taxation Association, 23, 75-90.

Cadot, O. (1987): Corruption as a Gamble. Journal of Public Economics, 33, 223-244. 
Cameron, L., Chaudhuri, A., Erkal, N. and Gangadharan, L. (2009): Propensities to engage in and punish corrupt behaviour: Experimental evidence from Australia, India, Indonesia and Singapore. Journal of Public Economics, 93, 843-851.

Cameron, A.C. and Trivedi, P.K. (2005): Microeconometrics - Methods and Applications. Cambridge University Press, Cambridge.

Charness, G. and Levin D. (2005): When Optimal Choices Feel Wrong: A Laboratory Study of Bayesian Updating, Complexity, and Affect. American Economic Review, 95, 13001309.

Chaudhuri, A. (2012): Gender and corruption: A survey of the experimental evidence. In: Serra, D. and Wantchekon, L. (eds.): New Advances in Experimental Research on Corruption, Research in Experimental Economics, Vol. 15, Emerald Books, Chapter 2.

Cherry, T. L., Frykblom, P., and Shogren, J. F. (2002). Hardnose the dictator. American Economic Review, 92, 1218-1221.

Croson, R, and Gneezy, U. (2009): Gender differences in preferences. Journal of Economic Literature, 47, 448-474.

DeGroot, M.H. and Schervish, M.J.(2012): Probability and Statistics. Pearson Education, Boston.

Di Tella, R. and Schargrodsky, E. (2003): The Role of Wages and Auditing During a Crackdown on Corruption in the City of Buenos Aires. Journal of Law and Economics, 46, 269-292.

Dohmen, T., Falk, A., Huffman, D. and Sunde, U. (2010): Are Risk Aversion and Impatience Related to Cognitive Ability. American Economic Review, 100, 1238-1260.

Dollar, D., Fisman, R. and Gatti, R. (2001):Are Women Really the "Fairer" Sex? Corruption and Women in Government. Journal of Economic Behavior and Organization, 46, 423-429.

Dusek, L., Ortmann, A. and Lizal, L. (2005): Understanding Corruption and Corruptibility Through Experiments: A Primer. Prague Economic Papers, 2, 147-162.

Eckel, C. amd Grossman, P. (2008): Men, Women and Risk Aversion: Experimental Evidence. In:Plott, C and Smith, V. (eds.): Handbook of Experimental Economics, Vol. 1, Elsevier, B.V., Chapter 113.

Fischbacher, U. (2007): z-Tree: Zurich Toolbox for Ready-made Economic Experiment. Experimental Economics, 10, 171-178.

Fisman, R., and Miguel, E. (2007): Corruption, Norms, and Legal Enforcement: Evidence from Diplomatic Parking Tickets. Journal of Political Economy, 115, 1020-1048.

Foltz, J.D. and Bromley, D.W. (2011): Highway Robbery: The Economics of Petty Corruption in West African Trucking. Paper presented at the $8^{\text {th }}$ Midwest International Economic Development Conference, University of Wisconsin - Madison 2011.

Frank, B., Lambsdorff, J.G., and Boehm, F. (2011): Gender and Corruption: Lessons from Laboratory Corruption Experiments, European Journal of Development Research, 23, 59-71. 
Frank, B., and Schulze, G. (2000): Does economics make citizens corrupt? Journal of Economic Behavior and Organization, 43, 101-113.

Frederick, S. (2005): Cognitive Reflection and Decision Making. Journal of Economic Perspectives, 19, 25-42.

Gill, D. and Prowse, V. (2012): A Structural Analysis of Disappointment Aversion in a Real Effort Competition. American Economic Review, 102, 469-503.

Gneezy, U., Leonard, K.L., and List, J.L. (2009): Gender Differences in Competition: Evidence From A Matrilineal and a Patriarchal Society. Econometrica, 77, 1637-1664.

Goeree, J.K., Holt, C., Palfrey, T. (2003): Risk Averse Behavior in Generalized Matching Pennies Games. Games and Economic Behavior, 45, 97-113.

Greiner, B. (2004): An Online Recruiting System for Economic Experiments. In: Kurt Kremer, Volker Macho (Eds.): Forschung und wissenschaftliches Rechnen 2003. GWDG Bericht 63, Goettingen: Ges. für Wiss. Datenverarbeitung, 79-93.

Holt, C., and Laury, S. (2002): Risk Aversion and Incentive Effects. American Economic Review, 92, 1644-1655

Jain, A. K. (2001): Corruption: A Review. Journal of Economic Surveys, 15, 71-121.

Kahneman, D. and Tversky, A. (1971): Belief in the law of small numbers. Psychological Bulletin, 76, 105-110.

Kahneman, D. and Tversky, A. (1973): On the Psychology of Prediction. Psychological Review, 80, 237-251.

Kahneman, D. and Tversky, A. (1983): Extensional versus Intuitive Reasoning: The Conjunction Fallacy in Probability Judgment. Psychological Review, 90, 293-315.

Kirchgässner, G. (1997): Auf der Suche nach dem Gespenst des Ökonomismus. Einige Bemerkungen über Tausch, Märkte und die Ökonomisierung der Lebensverhältnisse. Analyse und Kritik, 19, 127-152.

Lee, E.T. (1992): Statistical Methods For Survival Data Analysis. John Wiley, New York.

Lambsdorff, J. G. (2006): The Causes and Consequences of Corruption: What do we know from a cross-section of countries? In Rose-Ackerman, S. (ed.): International Handbook on the Economics of Corruption. Cheltenham UK: Edward Elgar Publishing.

Lambsdorff, J.G., and Frank, B. (2010): Bribing versus gift giving - An experiment. Journal of Economic Psychology, 31, 116-125.

Lambsdorff, J.G., and Frank, B. (2011): Corrupt Reciprocity - Experimental evidence on a men's game. International Review of Law and Economics, 31, 116-125.

Lilliefors, H. W. (1967): On the Kolmogorov-Smirnov tests for normality with mean and variance unknown. Journal of the American Statistical Association, 62, 399-402

Luce, R.D. (1959): Individual choice behavior. John Wiley, Oxford. 
Olken, B.A. (2007): Monitoring Corruption: Evidence from a Field Experiment in Indonesia. Journal of Political Economy, 115, 200-249.

Read, D., Loewenstein, G. and Rabin, M. (1999): Choice Bracketing. Journal of Risk and Uncertainty, 19, 171-197.

Rivas, M.F. (2013): An Experiment on Corruption and Gender. Bulletin of Economic Research, 65, $10-42$.

Rose-Ackerman, S. (1975): The economics of corruption. Journal of Public Economics, 4, 187-203.

Schulze, G. and Frank, B. (2003): Deterrence vs. Intrinsic Motivation: Experiment Evidence on the Determinants of Corruptibility. Economics of Governance, 4, 143-160.

Serra, D. (2010): Studying Corruption Through Experiments. In: Kreutner, M. (ed): Practice Meets Science. Contemporary Anti-Corruption Dialogue IACSS 2009, Vienna.

Serra, D. and Wantchekon, L. (2012): New Advances in Experimental Research on Corruption, Research in Experimental Economics, Vol. 15, Emerald Books.

Shleifer, A. and Vishny, R.W. (1993): Corruption. Quarterly Journal of Economics, 108, 599-617.

Siegel, S., and Castellan Jr., N.J. (1988): Nonparametric Statistics for the Behavioral Sciences. McGraw-Hill, New York.

Swamy, A., Knack, S., Lee, Y. and Azfar, O. (2001):Gender and Corruption, Journal of Development Economics, 64, 25-55

Thaler, R., and Johnson, E. (1990). Gambling with the house money and trying to break even: The effects of prior outcomes on risky choice. Management Science, 36, 643-660.

Transparency International (2010): Global Corruption Barometer 2010, Berlin.

Van Rijckeghem, C. and Weder, B. (2001): Bureaucratic corruption and the rate of temptation: do wages in the civil service affect corruption, and by how much? Journal of Development Economics, 65, 307-331.

Waithima, A.K. (2010): The role of gender, ethnicity and harambee in corruption: Experimental evidence from Kenya. Unpublished PhD thesis, Department of Economics, University of Cape Town, Cape Town, South Africa. 


\section{Appendix A: Instructions}

The instructions for both treatments and the lottery questionnaire were originally in German. The instructions presented here are the translation of the originally used ones.

\section{Instructions Treatment EARNED}

- During the experiment, all payments will be displayed in the fictional currency "Thaler”.

- The experiment consists of 10 periods.

- Your payout is independent of all other participants' decisions during all periods.

- Before the first period, a test period will be carried out.

- This test period has no impact on your payout and serves solely the better understanding of the experiment.

\section{Course of one period}

- Each period lasts 120 seconds.

- In each period you will be working on a task which entails positioning sliders in the middle of the scale, in the target position 50. You are allowed touse only the computer mouse. The task is displayed on the screen (see graphic below). You can work on any number of sliders, meaning that the order of the chosen sliders is irrelevant. Only correctly positioned sliders will be counted.

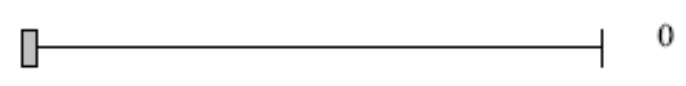

a) original position

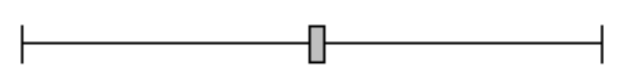

50

b) target position

- For each correctly positioned slider you will be credited 4T.

- At the end of the period you will receive feedback on how many sliders were positioned correctly and how many Taler you will be credited.

- Subsequently, you will be able to change your periodical payout by deciding whether to accept an additional payment.

- Thereafter, a new period starts. 


\section{Additional Payment}

- At the end of the period you may choose an additional payment. It is within your discretion to accept or reject the additional payment.

- In 8 out of 10 cases your current periodical payout will be increased by one quarter (Case 1).

- In 2 out of 10 cases you will not receive the additional payment. Moreover, from this moment on, you will receive solely $2 \mathrm{~T}$ for each correctly positioned slider until the end of the experiment. Hereby, you can only work on maximally 10 sliders (Case 2).

- If Case 2 occurs, you will not be offered an additional payment in the subsequent periods.

Your periodical payout consists of:

a) Current Periodical Payout $=$ (number of correctly positioned sliders) $\mathrm{x} 4 \mathrm{~T}$

b1) Additional Payment (in 8 out of 10 cases) $=\frac{1}{4} x$ Current Periodical Payout

b2) Additional Payment (in 2 out of 10 cases) $=0$

In each following period you will receive solely $2 \mathrm{~T}$ for each correctly positioned slider until the end of the experiment. Hereby, you can only work on maximally 10 sliders.

c) Periodical Payout $=$ Current Periodical Payout + Additional Payment

\section{Test Period}

- Before starting the experiment with period 1, a test period is carried out.

- In this test period you will be given the possibility to become acquainted with the task for the following periods.

- You will not receive a payout for correctly positioned sliders after the test period.

- At the end of the test period you will receive feedback on how many sliders you positioned correctly.

At the end of the experiment the sum of all periodical payouts will be exchanged according to the exchange rate 1EUR = 100T and paid out in cash together with the show-up fee of 2,50EUR. 


\section{Please note that:}

- Communication is not allowed.

- All mobile phones must be switched off during the whole experimental procedure.

- The decisions you make during this experiment will stay anonymous, i.e. no participant will know the name of a person who made a specific decision.

- The payments will also be distributed anonymously. No participant will know the sum another participant receives.

- Please remain seated in your cabin until the end of the experiment. For receiving your payout and the show-up fee, your cabin number will be called out.

Good Luck! 


\section{Instructions Treatment ENDOWED}

- During the experiment, all payments will be displayed in the fictional currency "Taler”.

- The experiment consists of 10 periods.

- Your payout is independent of the other participants' decisions during all periods.

\section{Course of one period}

- At the beginning of each period you will be given 80T.

- Subsequently, you will be able to change your periodical payout by deciding whether to accept an additional payment.

- Thereafter, a new period starts.

\section{Additional Payment}

- At the end of the period you may choose an additional payment. It is within your discretion to accept or reject the additional payment.

- In 8 out of 10 cases your current periodical payout will be increased by one quarter (Case 1).

- In 2 out of 10 cases you will not receive the additional payment. Moreover, from this moment on, you will receive solely $20 \mathrm{~T}$ at the beginning of each correctly positioned slider until the end of the experiment. (Case 2).

- If Case 2 occurs, you will not be offered an additional payment in the subsequent periods.

Your periodical payout consists of:

a) Current Periodical Payout $=80 \mathrm{~T}$

b1) Additional Payment (in 8 out of 10 cases) $=\frac{1}{4} \times 80 \mathrm{~T}=100 \mathrm{~T}$

b2) Additional Payment (in 2 out of 10 cases) $=0$

In each following period you will receive only $20 \mathrm{~T}$.

c) Periodical Payout $=$ Current Periodical Payout + Additional Payment

At the end of the experiment the sum of all periodical payouts will be exchanged according to the exchange rate $1 \mathrm{EUR}=100 \mathrm{~T}$ and paid out in cash together with the show-up fee of 2,50EUR.

\section{Please note that:}

- Communication is not allowed.

- All mobile phones must be switched off during the whole experimental procedure. 
- The decisions you make during this experiment will stay anonymous, i.e. no participant will know the name of a person who made a specific decision.

- The payments will also be distributed anonymously. No participant will know the sum another participant receives.

- Please remain seated in your cabin until the end of the experiment. For receiving your payout and the show-up fee, your cabin number will be called out.

Good Luck! 


\section{Instructions Questionnaire Lottery}

- The experiment is over now.

\section{Part I}

- In part I of the questionnaire we would like to know how you would choose between a safe payment (Alternative A) and a lottery (Alternative B).

- $\quad$ The following screen will be presented to you:

Bitte geben Sie in jeder Zeile an ob Sie die sichere Auszahlung (Alternative A) ODER die Lotterie (Alternative B) bevorzugen:

1) Alternative A: $0 €$ sicher $C \curvearrowright$ Alternative $B$ : mit $50 \%$ Wahrscheinlichkeit $30 €$ und mit $50 \%$ Wahrscheinlichkeit $0 €$.

2) Alternative A: $1 €$ sicher $\curvearrowright \subset$ Alternative $B$ : mit $50 \%$ Wahrscheinlichkeit $30 €$ und mit $50 \%$ Wahrscheinlichkeit $0 €$.

3) Alternative A: $2 €$ sicher $\curvearrowright \subset$ Alternative $\mathrm{B}$ : mit $50 \%$ Wahrscheinlichkeit $30 €$ und mit $50 \%$ Wahrscheinlichkeit $0 €$.

4) Alternative $A$ : $3 €$ sicher $\curvearrowright \subset$ Alternative $B$ : mit $50 \%$ Wahrscheinlichkeit $30 €$ und mit $50 \%$ Wahrscheinlichkeit $0 €$.

5) Alternative A: $4 €$ sicher $\curvearrowright \subset$ Alternative $\mathrm{B}$ : mit $50 \%$ Wahrscheinlichkeit $30 €$ und mit $50 \%$ Wahrscheinlichkeit $0 €$.

6) Alternative A: $5 €$ sicher $\curvearrowright \subset$ Alternative $B$ : mit $50 \%$ Wahrscheinlichkeit $30 €$ und mit $50 \%$ Wahrscheinlichkeit $0 €$.

7) Alternative A: $6 €$ sicher $\curvearrowright \subset$ Alternative $\mathrm{B}$ : mit $50 \%$ Wahrscheinlichkeit $30 €$ und mit $50 \%$ Wahrscheinlichkeit $0 €$.

8) Alternative A: $7 €$ sicher $\curvearrowright \subset$ Alternative $\mathrm{B}$ : mit $50 \%$ Wahrscheinlichkeit $30 €$ und mit $50 \%$ Wahrscheinlichkeit $0 €$.

9) Alternative A: $8 €$ sicher $C \subset$ Alternative $B$ : mit $50 \%$ Wahrscheinlichkeit $30 €$ und mit $50 \%$ Wahrscheinlichkeit $0 €$.

10) Alternative A: $9 €$ sicher $\curvearrowright \subset$ Alternative $B:$ mit $50 \%$ Wahrscheinlichkeit $30 €$ und mit $50 \%$ Wahrscheinlichkeit $0 €$.

11) Alternative A: $10 €$ sicher $\curvearrowright \subset$ Alternative $\mathrm{B}:$ mit $50 \%$ Wahrscheinlichkeit $30 €$ und mit $50 \%$ Wahrscheinlichkeit $0 €$

12) Alternative $A: 11 €$ sicher $\sim C$ Alternative $B$ : mit $50 \%$ Wahrscheinlichkeit $30 €$ und mit $50 \%$ Wahrscheinlichkeit $0 €$

13) Alternative A: $12 €$ sicher $\curvearrowright \subset$ Alternative $\mathrm{B}:$ mit $50 \%$ Wahrscheinlichkeit $30 €$ und mit $50 \%$ Wahrscheinlichkeit $0 €$

14) Alternative A: $13 €$ sicher $C \curvearrowright$ Alternative $B:$ mit $50 \%$ Wahrscheinlichkeit $30 €$ und mit $50 \%$ Wahrscheinlichkeit $0 €$

15) Alternative $A: 14 €$ sicher $\subset \subset$ Alternative $B:$ mit $50 \%$ Wahrscheinlichkeit $30 €$ und mit $50 \%$ Wahrscheinlichkeit $0 €$

16) Alternative A: $15 €$ sicher $\curvearrowright \subset$ Alternative $B:$ mit $50 \%$ Wahrscheinlichkeit $30 €$ und mit $50 \%$ Wahrscheinlichkeit $0 €$

17) Alternative $A: 16 €$ sicher $\subset \subset$ Alternative $B:$ mit $50 \%$ Wahrscheinlichkeit $30 €$ und mit $50 \%$ Wahrscheinlichkeit $0 €$.

18) Alternative A: $17 €$ sicher $\subset \subset$ Alternative $B:$ mit $50 \%$ Wahrscheinlichkeit $30 €$ und mit $50 \%$ Wahrscheinlichkeit $0 €$

19) Alternative A: $18 €$ sicher $C \curvearrowright$ Alternative $\mathrm{B}:$ mit $50 \%$ Wahrscheinlichkeit $30 €$ und mit $50 \%$ Wahrscheinlichkeit $0 €$

20) Alternative A: $19 €$ sicher $C \subset$ Alternative $B:$ mit $50 \%$ Wahrscheinlichkeit $30 €$ und mit $50 \%$ Wahrscheinlichkeit $0 €$. 
- In each line (from 1 to 20) you have two options:

o A safe payment (Alternative A).

o An “all-or-nothing”-lottery:

- With a chance of $50 \%$ you can win 30EUR

- With a chance of 50\% you win 0EUR (Alternative B).

- Please choose for each line either alternative A or B. Mark the left field if you choose Alternative A or the right field if you choose Alternative B.

\section{Additional profit opportunity in part I of the questionnaire:}

- In the first part of the questionnaire you have another chance to win a payment.

- Every $14^{\text {th }}$ participant wins, meaning that two participants in this room will be randomly drawn.

- After answering the second part of the questionnaire, two randomly chosen participants will draw two lines that will be paid out to the two winners. Hereby, the randomly chosen participants will draw numbered cards from a bag containing cards from 1 to 20 for each line. The drawn line will be noted and put aside for the second draw.

- For the drawing of the two winners, two different participants will be asked to randomly draw numbered cards ranging from 1 to 28.

- The chosen participants will receive their additional payout when all payoffs will be distributed after answering the second part of the questionnaire.

- If you are one of the chosen participants and decided to take Alternative B for the line which will be paid out, you will be asked to cast a ten-sided dice. With the numbers 1 to 5 you receive 30EUR, with 6 to 10 you receive nothing. If you decided to take Alternative A, you will receive the safe payout immediately.

When all participants complete the first part of the questionnaire, part II will follow.

The answers in part II are irrelevant for the payout.

All questions will be evaluated anonymously and communication is not allowed during the complete experiment.

Thank you very much for your participation in this experiment! 


\section{Appendix B: Derivation of rational choice behavior}

Recall from our experimental design that subjects can increase their income by $25 \%$ at the end of each period by accepting the bribe. However, if they are detected with a probability of $20 \%$ their income in the current period remains unchanged and they receive an amount of only 20 Taler in all remaining periods. We derive the rational choice behavior of a risk-neutral, expected utility maximizer in all possible periods of our experiment. For our calculus we use the income value of 192 Taler which is the maximum amount that can be earned in one period when solving all the 48 sliders. Thus, our calculus is in fact an upper bound with lower income values yielding to the same qualitative results. As summarized in Table B.1, it is only rational to accept the bribe if 1 or 2 periods are remaining. Regarding a time horizon of 10 periods accepting the bribe is therefore only from period 9 on a dominant strategy.

Table B.1: Expected Value (EV) for each possible choice with different number of periods remaining

\begin{tabular}{clcc}
\hline $\begin{array}{c}\text { \# of periods } \\
\text { remaining }\end{array}$ & EV if bribe is accepted $(\mathrm{B})$ & EV if bribe is not accepted $(\mathrm{N})$ & Expected Choice \\
\hline 1 & $0.8^{*}\left(192^{*} 1.25\right)+0.2^{*} 192=230.4$ & 192 & $\mathrm{~B}$ \\
2 & $0.8^{*}(240+230.4)+0.2^{*}(192+20)=418.72$ & $2^{*} 192=388$ & $\mathrm{~B}$ \\
3 & $0.8^{*}(240+418.72)+0.2^{*}(192+40)=572.4$ & $3^{*} 192=576$ & $\mathrm{~N}$ \\
4 & $0.8^{*}(240+576)+0.2^{*}(192+60)=702.4$ & $4 * 192=768$ & $\mathrm{~N}$ \\
5 & $0.8^{*}(240+768)+0.2^{*}(192+80)=840.8$ & $5^{*} 192=960$ & $\mathrm{~N}$ \\
6 & $0.8^{*}(240+960)+0.2^{*}(192+100)=1018.4$ & $6^{*} 192=1152$ & $\mathrm{~N}$ \\
7 & $0.8^{*}(240+1152)+0.2^{*}(192+120)=1176$ & $7^{*} 192=1344$ & $\mathrm{~N}$ \\
8 & $0.8^{*}(240+1344)+0.2^{*}(192+140)=1333.6$ & $8^{*} 192=1536$ & $\mathrm{~N}$ \\
9 & $0.8^{*}(240+1536)+0.2^{*}(192+160)=1491.2$ & $9 * 192=1728$ & $\mathrm{~N}$ \\
10 & $0.8^{*}(240+1728)+0.2^{*}(192+180)=1648.8$ & $10^{*} 192=1920$ & $\mathrm{~N}$ \\
\hline
\end{tabular}




\section{Appendix C: Derivation of risk preferences}

We follow the analytical approach by Holt/Laury (2002) and Goeree/Holt/Palfrey (2003) to evaluate risk preferences when using lottery choices in a multiple price list format. We capture the corresponding coefficients by using choice probabilities that are derived from an underlying additive random utility model (Cameron/Trivedi 2005). To be more specific let the safe option A yield in any row the payoff $s$ and the utility $U^{*}(s)$. The lottery option $B$ gives the expected payoff $L$ and the utility $\mathrm{U}^{*}(\mathrm{~L})$. Because these two utilities are latent variables and thus cannot be observed, we can only specify choice probabilities about preferring one alternative over the other, so that

$$
\begin{aligned}
& \mathrm{U}^{*}(\mathrm{~s})=\mathrm{U}(\mathrm{s})+\varepsilon_{1} \\
& \mathrm{U}^{*}(\mathrm{~L})=\mathrm{U}(\mathrm{L})+\varepsilon_{2}=\left(0.5^{*} \mathrm{U}(30)+0.5^{*} \mathrm{U}(0)\right)+\varepsilon_{2},
\end{aligned}
$$

where $\mathrm{U}(\mathrm{s})$ and $\mathrm{U}(\mathrm{L})$ are the utility of choosing $\mathrm{A}$ and $\mathrm{B}$ respectively and $\varepsilon_{1}, \varepsilon_{2}$ the random components of utility. Let y be the observed decision which alternative was chosen. We set $y=1$ if $U^{*}(s)>U^{*}(L)$ which means that the safe option was preferred over the lottery. The probability for this random event is then given by:

$$
\begin{aligned}
\operatorname{Pr}[\mathrm{y}=1] & =\operatorname{Pr}\left[\mathrm{U}^{*}(\mathrm{~s})>\mathrm{U}^{*}(\mathrm{~L})\right] \\
& =\operatorname{Pr}\left[\mathrm{U}(\mathrm{s})+\varepsilon_{1}>\mathrm{U}(\mathrm{L})+\varepsilon_{2}\right] \\
& =\operatorname{Pr}\left[\varepsilon_{2}-\varepsilon_{1}<\mathrm{U}(\mathrm{s})-\mathrm{U}(\mathrm{L})\right] \\
& =\mathrm{F}(\mathrm{U}(\mathrm{s})-\mathrm{U}(\mathrm{L})),
\end{aligned}
$$

with $\mathrm{F}(\cdot)$ being the cumulative distribution function of $\left(\varepsilon_{2}-\varepsilon_{1}\right)$.

Using the probabilistic choice function by Luce (1959) that takes the shape of a logistic function assuming the random components to be distributed independently of Type 1 extreme value the probability of the random event $\mathrm{y}=1$ can then be expressed by:

$$
\operatorname{Pr}[\mathrm{y}=1]=1 /(1+\exp (\lambda *(\mathrm{U}(\mathrm{L})-\mathrm{U}(\mathrm{s}))) \text {. }
$$

This probability function allows for noise in the decision-making process as it is assumed that subjects may make mistakes in filling out the table due to insensitivity in payoff differences. The noise parameter is denoted by $\lambda$ and is reversely related to the variance of the errors. Smaller values of $\lambda$ imply larger amount of errors leading to choice probabilities of exactly 0.5 , while large values of $\lambda$ will show a clear tendency towards option A or option B. Consistent with the literature we employ a utility function with constant relative risk aversion $\mathrm{U}(\mathrm{x})=\mathrm{x}^{1-\mathrm{r}}$ and normalize it to avoid scaling effects on $\lambda$. By setting $U(x)=x^{1-r} / 30^{1-r}$ we ensure that the utility of all outcomes is bounded between 0 and 1 where the highest possible outcome of 30 units gets utility of 1 and the lowest possible outcome of 
zero units utility of 0 accordingly. The normalized utility of option B is therefore 0.5 so that the probability of $\mathrm{y}=1$ simplifies to:

$\operatorname{Pr}[\mathrm{y}=1]=1 /\left(1+\exp (\lambda *(0.5-\mathrm{U}(\mathrm{s})))=1 /\left(1+\exp \left(\lambda *\left(0.5-\left(\mathrm{s}^{1-\mathrm{r}} / 30^{1-\mathrm{r}}\right)\right)\right)\right.\right.$.

Using maximum likelihood estimation on all rows of the table simultaneously we are able to derive the r-coefficients and the noise parameter $\lambda$ out of the binary choices made by all subjects in the experiment. 